\title{
The effects of $2.5 \%$ RADA self-assembling peptide on epithelization, number of fibroblast and degree of collagen in a dilated colon after a purposed mechanical bowel obstruction in Wistar rats
}

\author{
Reno Rudiman*, Jini Suraya, Nurhayat Usman
}

\author{
Department of Surgery, Division of Digestive Surgery, Hasan Sadikin Hospital/Faculty of Medicine, Padjadjaran \\ University, Bandung, West Java Indonesia
}

Received: 07 April 2016

Accepted: 10 May 2016

\section{*Correspondence: \\ Dr. Reno Rudiman, \\ E-mail: rudiman@unpad.ac.id}

Copyright: (C) the author(s), publisher and licensee Medip Academy. This is an open-access article distributed under the terms of the Creative Commons Attribution Non-Commercial License, which permits unrestricted non-commercial use, distribution, and reproduction in any medium, provided the original work is properly cited.

\begin{abstract}
Background: An intestinal anastomosis leakage is a complication that must be prevented as the prevalence of this leakage is $0,5-21 \%$ in gastrointestinal anastomosis commonly and $1-12 \%$ in a colon anastomosis and $10-14 \%$ in low anterior colorectal resection anastomosis. Serosa is an important part as first integrity in the healing of bowel anastomosis. The application of $2.5 \%$ RADA self-assembling peptide may increase the healing process of anastomosis as a fibrin seal in serosa. This study was designed to determine the effects of $2.5 \%$ RADA selfassembling peptide on the healing process of colorectal anastomosis, judging from the degree of epithelization, number of fibroblasts, and degree of collagen in a dilated colon after a purposed obstruction.

Methods: This was an experimental study. Research subjects included 18 male Wistar rats that meet the inclusion and exclusion criteria, randomly divided into 2 groups, 9 rats were using 2.5\% RADA self-assembling peptide and the others were not using 2.5\% RADA self-assembling peptide. The research subjects were given the topical $2.5 \%$ RADA self-assembling peptide applying on serosa of colorectal after an anastomosis. All rats were sacrificed on the seventh day after anastomosis, and tissue sample of the anastomosis site were obtained for histopathological evaluations. The degree of epithelization, number of fibroblasts, and degree of collagen were evaluated by scoring methods. The Mann-Whitney was used to analyze a statistical significant $(\mathrm{p}<0.05)$.

Results: The mean epithelization in $2.5 \%$ RADA self-assembling peptide group was significantly higher than the mean epithelization in without $2.5 \%$ RADA self-assembling peptide group, similar with collagen degree in administration of $2.5 \%$ RADA self-assembling peptide group. It also showed a significant difference compared to without $2.5 \%$ RADA self-assembling peptide group. While the number of fibroblasts in the administration of $2.5 \%$ RADA self-assembling peptide group did not have a significant difference compared to the number of fibroblasts in the with $2.5 \%$ RADA self-assembling peptide group.

Conclusions: The administration of $2.5 \%$ RADA self-assembling peptide on healing anastomosis colonic obstruction in Wistar rats was significantly promoted anastomosis healing. However, further research is needed before applying the agent on human practice.
\end{abstract}

Keywords: $2.5 \%$ RADA self-assembling peptide, Colorectal anastomosis, Epithelization, Fibroblasts, Collagen

\section{INTRODUCTION}

Leakage of intestinal anastomosis is a feared complication in gastrointestinal surgery. ${ }^{1,2}$ After the progress achieved in colorectal surgery, a good healing in intestinal anastomosis after resection of colon and rectal remains a challenge. The prevalence of intestinal leakage is generally 0.5 to $21 \%$ after colorectal surgery. Specifically, 1-12\% post anastomosis of colorectal, 10$14 \%$ in the lower resection of colorectal. Goligher in 
1970 , found the radiological leak as much as $69 \%$ in patients with colorectal anastomosis low on routine barium enema examination, 5-7 days post-surgery. ${ }^{3}$ Mortality after anastomotic leakage is as much as 6-39\% and the risk of permanent stoma as much as $1-10 \%$. $^{4}$

Risk factors that influence a good healing of anastomosis of the colon include: age, sex of the patient, body mass index, the status of good nutrition without systemic disorders, absence of contamination of the stool both in the colorectal and the environment around the colorectal, access and good exposure to colorectal, stump with the condition of blood supply, anastomosis are not tense, to avoid obstruction distal, the drain in the pelvis, the distance to the anal verge, a meticulous anastomosis technique, the condition of intraoperative such as operating time, blood pressure, the amount of blood loss, and the use of drugs such as steroid and non-steroid antiinflammatory drugs. ${ }^{3,5-8,10,11}$

In 1887, Halsted found that the content of collagen in the submucosal layer were the main factors that play a role in healing process of intestinal anastomosis. ${ }^{12}$ The most important stage in the formation of collagen is the process of hydroxylation of proline at hydroproline maturation phase, which will determine strength of the structure site of anastomosis. This strength is usually measured by the ability to withstand pressure anastomosis, where the resistance reaches $60 \%$ in the $3 \mathrm{rd}$ to 4 th postoperative, and reached $100 \%$ on the 7 th day. In order to achieve good anastomosis, the layers serosa stich (visceral peritoneum) should have a better strength than the muscular layer. ${ }^{1,13}$ Serosa layer is an extension of the peritoneal and has an important role of watertight seal on the inner side of the intestine. Serosa layer is an important structure that maintains good anastomosis. As can be seen extraperitoneal intestine that has no serosal layer such as esophagus and rectum, shows higher leakage rate. Early integrity in wound healing anastomosis is dependent on fibrin seal on the serosa side, compliance to the standards watertight and good suture on the intestinal wall, in this case the submucosal layer. $^{14,15}$

2.5\% RADA self-assembling peptide is a liquid synthetic hydrogel material composition containing argininealanine-aspartate acid that when in contact with blood or body fluids under physiological condition will produce haemostatic condition and able to assemble themselves to form nanofibers, a condition similar to the extracellular matrix. ${ }^{16,17}$ Since the $2.5 \%$ RADA self-assembling peptide is a synthetic material, it does not pose a threat of the spread of the virus when in contact with patients' blood component, anaphylactic shock as a result of the response to foreign proteins and infections that can lead to diseases such as bovine spongiform encelopathy (BSE) ${ }^{18}$ Previously, has been studied extensively the use of liquid fibrinogen and thrombin (fibrin glue) to protect the intestinal anastomosis. Research in Denmark by Nordentoft et al in 2007 proved that using of fibrin glue for the benefit of intestinal anastomosis healing results showed difference between conventional anastomosis, so that use of fibrin glue in intestinal anastomosis is safe. ${ }^{19}$ While Portilla-de Buen et al in 2014 stated that the fibringlue with higher thrombin levels is better in the case of the left colon anatomosis with ischemic risk. Fibrin glue derived from animal plasma component carries risk of allergic reaction. While fibrin glue derived from human plasma carries risk of infection. ${ }^{20}$

The presence of $2.5 \%$ RADA self-assembling peptide with its advantages derived from a synthetic material, so that it can prevent complications due to the use and see the effect on the ability to make nanofibers similar to the extracellular matrix as prevention of leakage in colonic anastomosis leakage is interesting to know that no research of the use of $2.5 \%$ RADA self-assembling peptide in preventing anastomosis leakage previously. ${ }^{16,17}$ If it is proven, that $2.5 \%$ RADA self-assembling peptide plays a role in wound healing process of colorectal anastomosis, it can be considered to be used as a wound adjunct in the prevention of anastomotic leakage in colorectal surgery. Theoretically, the 3D matrix, being derived from synthetic material, has no allergic nor infection risks.

\section{METHODS}

This was an experimental study. It was conducted on November-December 2015 at Bio Farma animal laboratory Bandung and Hasan Sadikin Hospital Bandung, Indonesia. This experiment was using 18 Wistar rats that were divided into 2 groups, the $2.5 \%$ RADA self-assembling peptide group and non $2.5 \%$ RADA self-assembling peptide group. The Inclusion criteria used in this study were as follows: (a) Wistar rats aged 3 to 6 months; (b) male sex; (c) weight 200-300 grams; (d) in healthy conditions; (e) nutrition is given equally both in quality and quantity. On the day 1 , first laparotomy was done to obtain the condition of mechanical bowel obstruction by tying loose silk 3.0 at colorectal section for 3 days. On day-4 the second laparotomy were done to obtain a resection and colorectal anastomosis with PGA 5.0. For the $2.5 \%$ RADA selfassembling peptide group we applied $2.5 \%$ RADA selfassembling peptide along the anastomosis suture and for non $2.5 \%$ RADA self-assembling peptide, we did not apply anything. The $2.5 \%$ RADA self-assembling peptide was kept at a temperature of $2-8^{\circ}$ Celsius in order not to damage before use. On Day-11, we sacrificed the whole Wistar rats in both groups with excessive dose of anesthesia. The anastomotic wound site was resected 1 $\mathrm{cm}$ upper and $1 \mathrm{~cm}$ lower from the site. We examined the epithelization, the number of fibroblast and the degree of collagen from the paraffin block prepared with hematoxillin-eosin (H\&E) staining, light microscopy with magnification 10X. Healing of gastrointestinal part was the same with the healing of the cutaneous wounds. Parameter used in this research was the same with parameter that $\mathrm{P}$ Gal et al presented in 2008 for cutaneous 
wounds healing in Sprague-Dawley rats as shown on Table $1 .{ }^{21}$ Data were collected and analyzed for normality of distribution with Shapiro-Wilk test. Because of the data were distributed not normally, the comparison were analyzed using Mann-Whitney Test.

\section{RESULTS}

Eighteen male Wistar Rats were included in the study. The scale of epithelization, number of fibroblast and degree of collagen can be seen in Table 1. The comparison of epithelization, number of fibroblast and degree of collagen between groups of $2.5 \%$ RADA selfassembling peptide and group without $2.5 \%$ RADA selfassembling peptide are shown on Table 2.

Table 1: The scale of epithelization, number of fibroblast and degree of collagen.

\begin{tabular}{|llll|}
\hline Scale & $\begin{array}{l}\text { Epthelization } \\
\text { Thickness of cut } \\
\text { edges }\end{array}$ & Fibroblast & Absent \\
\hline $\mathbf{1}$ & $\begin{array}{l}\text { Migration of cells } \\
(<50 \%)\end{array}$ & $\begin{array}{l}\text { Mild } \\
\text { Surrounding } \\
\text { Tissue }\end{array}$ & $\begin{array}{l}\text { Minimal } \\
\text { Granulation } \\
\text { Tissue }\end{array}$ \\
\hline $\mathbf{2}$ & $\begin{array}{l}\text { Migration of cells } \\
(\geq 50 \%)\end{array}$ & $\begin{array}{l}\text { Mild } \\
\text { Granulation } \\
\text { Tissue }\end{array}$ & $\begin{array}{l}\text { Mild } \\
\text { Granulation } \\
\text { Tissue }\end{array}$ \\
\hline $\mathbf{3}$ & $\begin{array}{l}\text { Bridging the } \\
\text { excision }\end{array}$ & $\begin{array}{l}\text { Moderate } \\
\text { Granulation } \\
\text { Tissue }\end{array}$ & $\begin{array}{l}\text { Moderate } \\
\text { Granulation } \\
\text { Tissue }\end{array}$ \\
\hline $\mathbf{4}$ & Keratinization & $\begin{array}{l}\text { Marked } \\
\text { Granulation } \\
\text { Tissue }\end{array}$ & $\begin{array}{l}\text { Marked } \\
\text { Granulation } \\
\text { Tissue }\end{array}$ \\
\hline
\end{tabular}

The results of statistical analysis with Mann Whitney test at $95 \%$ confidence level showed there were statistically differences in the degree of epithelization between the two groups. The number of fibroblast showed no significant difference between two groups and the degrees of collagen between the the two groups was statistically significant.

\section{DISCUSSION}

Based on the statistical analysis above, significant results were obtained between $2.5 \%$ rada self-assembling peptide to without $2.5 \%$ RADA self-assembling peptide on the degree of epithelization and collagen degrees. In general, the gastrointestinal tract, the submucosal are composed of large amounts of collagen and elastic connective tissue, and supports the nervous and vascular structures.12 Meanwhile, serosa is the layer that is an extension of the peritoneal and has an important role to role watertight seal on the inner side of the intestine. ${ }^{14}$

There is a significant reduction in the power margin, in the first week due to collagenolysis. Lysis of collagen due to the role of collagenase derived from neutrophils, macrophages and intraluminal bacteria such as Pseudomonas aeruginosa. Collagenase activity was largely in the first 3-5 days, which resulted in the decline in the amount of collagen so that the collagen synthesis begins. The synthesis of collagen started by fibroblast and smooth muscle cells. In the colon, collagen synthesis is more active than cutaneus part. ${ }^{13}$

In colonic obstruction, there is an increased activity of collagenase potential and decrease the concentration of hydroxyproline useful for the formation of collagen, so it has the potential for the anastomosis dehiscence. ${ }^{1}$ The use of $2.5 \%$ RADA self-assembling peptide in the wound has the objective in healing for the watertight condition of anastomosis. The advantage of $2.5 \%$ RADA selfassembling peptide is the ability to set up a network similar to the formation of matrix metalloproteinase work when in contact with body fluids or blood, $\mathrm{pH}$ and salt concentration. $^{14}$ This, of course, will help in the colorectal anastomosis wound healing, because the early integrity of the intestinal anastomosis healing is helping by the presence of fibrin seal function in serosa layer which is assisted by $2.5 \%$ RADA self-assembling peptide. ${ }^{18}$

Table 2: Comparison of epithelization, number of fibroblast and degree of collagen.

\begin{tabular}{|ccccccc|}
\hline \multirow{2}{*}{ Variable } & \multicolumn{2}{c}{ Groups } & & & & \\
& \multicolumn{2}{c}{$2.5 \%$ RADA self-assembling peptide } & \multicolumn{2}{c|}{ Without 2.5\% RADA self-assembling peptide } \\
\cline { 2 - 7 } & Mean $( \pm$ SD $)$ & Median & P value & Mean $( \pm$ SD $)$ & Median & P value \\
\hline Epithelization & $3.67( \pm 0.50)$ & $4.00(3.00-4.00)$ & 0.001 & $1.67( \pm 0.33)$ & $2.00(1.00-2.00)$ & 0.001 \\
\hline Number of Fibroblast & $2.11( \pm 1.05)$ & $2.00(1.00-4.00)$ & 0.054 & $2.39( \pm 0.97)$ & $4.00(2.00-4.00)$ & 0.054 \\
\hline Degree of Collagen & $3.00( \pm 0.73)$ & $3.00(1.00-3.00)$ & 0.005 & $1.33( \pm 0.50)$ & $1.00(1.00-2.00)$ & 0.005 \\
\hline
\end{tabular}

Comparison between groups of $2.5 \%$ RADA self-assembling peptide and group without $2.5 \%$ RADA self-assembling peptides.

The epithelization and the degree of collagen on $2.5 \%$ RADA self-assembling peptide administration group was statistically significant. This means that with the good integrity of serosal layer that achieving watertight function, then the growth of epithelial intestinal mucosa is better. The formation of collagen and the collagenolysis process can occur more rapid due to the integrity of the anastomosis wound healing. 1
The number of fibroblasts in the group given $2.5 \%$ RADA self-assembling peptide and in the group without $2.5 \%$ RADA self-assembling peptide showed no statistically significant differences with. This is happened, because the whole process among collagenolysis and collagen formation has occurred in each group on the seventh day for all stages. The number of fibroblasts is more in the group with a $2.5 \%$ RADA 
self-assembling peptide. This could mean that the fibroblast formation has been achieved prior to the formation of collagen. ${ }^{14}$

\section{CONCLUSION}

Based on the results of research and discussion, it can be concluded that the administration of $2.5 \%$ RADA selfassembling peptide on anastomosis healing in dilated colonic obstruction in Wistar rats yielded significant results in terms of increasing the degree of epithelization and degree of collagen compared to those without $2.5 \%$ RADA self-assembling peptide, but no results were significant in the number of fibroblast cells. The application of 3D-Matrix maybe is useful in lowering the leakage rate in colorectal anastomosis. However, we need a further research to examine whether it can be used in human.

\section{Funding: No funding sources}

Conflict of interest: None declared

Ethical approval: The study was approved by the institutional ethics committee

\section{REFERENCES}

1. Rehn M. Experimental Colonic Obstruction and Anastomotic Healing, Malmö, Lund University Faculty of Medicine. 2012: 9-41.

2. Trencheva K, Morrissey KP, Wells M, Mancuso CA, Lee SW, Sonoda T, et al. Identifying Important Predictors for Anastomosis Leak After Colon and Rectal Resection. Annals of Surgery. 2013;257;10813.

3. Bielecki K, Gajda A. The Causes and Prevention of Anastomotic Leak After Colorectal Surgery. Klinicka Onkologie Zvăštnǐ Cǐslo. 1999;12:25-30.

4. Boccola M, Lin Joshua, Rozen W, Ho YH. Reducing Anastomotic Leakage in Oncologic Surgery- an Evidence-Based Review. Anticancer Research. 2010;30:601-8.

5. Lin JK, Yueh TC, Chang SC, Lin CC, Lan YT, Wang HS. The influence of fecal diversion and anastomotic leakage on survival after resection of rectal cancer. J Gastrointest Surg. 2011;15(12):2251-61.

6. Mortensen NJ, Ashraf S. Intestinal Anastomosis In Gastrointestinal Tract and Abdomen Decker Inc ACS Surgery. 2008:1-15.

7. Khan MUN, Abir F, Longo W, Kozol R. Anastomotic Disruption After Large Bowel Resection. World J Gastroenterology. 2008;12(16):2497-504.

8. Telem DA, Chin EH, Nguyen SQ, Divino CM. Risk Factors for Anastomotic Leak Following Colorectal Surgery-A Case Control Study. Arch Surgery, 2010;145(4):371-6.
9. Choudhuri AH, Unppal R, Kumar M. Influence of Non-Surgical Risk Factors on Anastomotic Leakage after Major Gastrointestinal Surgery: Audit From A Tertiary Care Teaching Institute. International Journal of Critical Illness and Injury Science. 2013;3(4):246-9.

10. Suding P, Jensen E, Abramson MA, Itani K, Wilson SE. Definitive Risk Factors For Anastomotic Leaks in Elective Open Colorectal Resection. Arch Surgery. 2008;143(9):907-12.

11. Daams F, Luyer M, Lange JF. Colorectal anastomotic Leakage-Aspects of Prevention, Detection and treatment. World Journal of Gastroenterology. 2013;19(15):2293-7.

12. Halsted W. Circular suture of the intestine - an experimental study. Am J Med Sci. 1887;188:43660.

13. Kelli M, Bullard D, Rothenberger D. Colon, Rectum and Anus In Brunicardi FC, Andersen D, Billiar T, DunnD, HunterJ, Matthews J,Pollock R Penyunting : Schwartz's Principle of Surgery, 10th Ed, Mc Graw-Hill Companies; 2015:1175-1240.

14. Barbul A, Efron D, Kavalukas S. Wound Healing In Brunicardi FC, Andersen D, Billiar T, DunnD, HunterJ, Matthews J,Pollock R Penyunting : Schwartz's Principle of Surgery, 10th Ed, 2015, Mc Graw-Hill Companies; 2015:242-271.

15. Chen C. The Art of Bowel Anastomosis, Scandinavian. Journal of surgery. 2012;101:238-40.

16. Yoshida M, Goto N, Kawaguchi M, Koyama H, Kuroda J, Kitahora T, et al. Initial Clinical Trial of a Novel Hemostat, TDM-621, In The Endoscopic Treatments of the Gastric Tumors. Journal of Gastroenterology and Hepatology. 2014;29:77-9.

17. Masuhara H. Novel Infectious Agent-Free Hemostatic Material (TDM-621) in Cardiovascular Surgery. Annals of Thoracic Cardiovascular Surgery. 2012:1-8.

18. Puramatrix $2.5 \%$ RADA self-assembling peptide Medical Technology: Available at www.puramatrix.com/puramatrix_technology.html. Accessed 0ctober 8th 2015.

19. Nordentoft T, Rǿmer J,Sǿrensen M. Sealing of Gastrointestinal Anastomoses with A Fibrin GlueCoated Collagen Patch : A Safety Study. Journal Invest Surgery. 2007;6:363-9.

20. Portilla-de Buen E, Orozco-Mosqueda A, LealCortés C, Vázquez-Camacho G, Fuentes-Orozco C, Alvarez-Villaseñor AS, et al. Fibrinogen and Thrombin Concentration Are Critical For Fibrin Glue Adherence In Rat High-Risk Colon Anastomoses. Clinics. 2014;69(4):259-64.

21. Gal P. Kilik R. Mokry M. Vidinsky B. Et al. Simple Method of open skin wound healing model in corticosteroid-treated and diabetic rats: standardization of semi-quantitative and quantitative histological assessments. Veterinarni Medicina. 2008;53(12):652-9.

Cite this article as: Rudiman R, Suraya J, Usman $\mathrm{N}$. The effects of $2.5 \%$ RADA self-assembling peptide on epithelization, number of fibroblast and degree of collagen in a dilated colon after a purposed mechanical bowel obstruction in Wistar rats. Int Surg J 2016;3:1176-9. 